Article

\title{
Fabrication and Characterization of Ceftizoxime-Loaded Pectin Nanocarriers
}

\author{
Pawan Kumar ${ }^{1}\left(\right.$, Vinod Kumar ${ }^{2}\left(\mathbb{D}\right.$, Ravinder Kumar ${ }^{3}$ and Catalin Iulian Pruncu $4,5, *(\mathbb{C}$ \\ 1 Department of Materials Science and Nanotechnology, Deenbandhu Chhotu Ram University of Science and \\ Technology, Murthal 131039, India; pawankamiya@yahoo.in \\ 2 Department of Bio and Nano Technology, Guru Jambheshwar University of Science and Technology, \\ Hisar 125001, India; rs170090180003@gjust.org \\ 3 Department of Mechanical Engineering, Lovely Professional University, Phagwara 144411, India; \\ rav.chauhan@yahoo.co.in \\ 4 Mechanical Engineering Department, University of Birmingham, Birmingham B15 2TT, UK \\ 5 Mechanical Engineering, Imperial College London, Exhibition Rd., London SW7 2AZ, UK \\ * Correspondence: c.pruncu@imperial.ac.uk
}

Received: 21 June 2020; Accepted: 21 July 2020; Published: 24 July 2020

check for updates

\begin{abstract}
Ceftizoxime $\left(\mathrm{C}_{13} \mathrm{H}_{12} \mathrm{~N}_{5} \mathrm{NaO}_{5} \mathrm{~S}_{2}\right)$ is a parenteral, third-generationcephalosporin antibiotic used to treat bacterial infections including ear, nose, and throat infections. In this work, pectin has been used as a nanocarrier for ceftizoxime due to its high biocompatibility and non-toxicity with tunable surface properties. Ceftizoxime-loaded pectin nanocarriers (CPN) were successfully synthesized by the solvent displacement method. Optimization of nanoformulation was done by response surface methodology using Design-Expert software. The optimized formulation examined various in-vitro characterizations such as particle size, morphology, and FTIR studies. TEM results revealed irregular shape nanoparticles within the range of 29-110 $\mathrm{nm}$. The in-vitro drug release using the dialysis method was performed after $24 \mathrm{~h}$ where nanoformulation showed sustained drug release. Drug-loaded nanoparticles revealed good antimicrobial activity against Bacillus cereus, Bacillus polymyxa, Enterobacter aerogenes, and Pseudomonas aeruginosa.
\end{abstract}

Keywords: Ceftizoxime; pectin; solvent displacement; nanocarriers; antibacterial activity

\section{Introduction}

The oral drug administration route is very common and convenient for drug delivery [1]. However, it is not always the right path for some effective drug constituents, such as NSAIDs, peptides, or proteins which may poorly be absorbed and damage the mucosa in the stomach [2,3]. Many scientists tried new excipients for the development of effective drug carrier systems [4]. These drug carrier systems are capable of delivering the drug at the specific site of action and at the required time with the required amount [5]. Nanocarrier-based targeted drug delivery systems enabled the effective delivery of drug agents than conventional drug delivery systems such as solutions, lotions, creams, ointments, powders, suppositories, suspensions, injectable, pills, capsules and tablets [6]. Nanotechnology could play a fundamental role as nano-systems have shown their potential as the ideal drug delivery systems for poorly soluble, low absorption and unstable drugs [7]. Polymers such as chitosan, gelatin, cellulose, pectin are used to protect drugs from the physiological environment and prolong the release of drugs to improve its stability [8]. They are also mostly used as stabilizers, taste-making agents, and proactive agents [9]. The lack of toxicity and the low production costs of pectin make them a good choice for drug delivery purposes [10]. Pectin is a water-soluble, high molecular weight complex polysaccharide used in oral drug delivery systems [11] such as gastro-retentive systems, colon-specific 
delivery systems and mucoadhesive delivery systems [12]. Due to its biodegradable and biocompatible nature, this polymer used in pharmaceutical [13,14] and food industries [14,15]. Such features make pectin attractive for the preparation of a new and effective drug delivery system for cancer treatment, a combined multiple-cargo system consisting of the hydrophobic drugs [11]. The properties such as easy dissolution in a basic aqueous medium and gel formation in the acidic environment are more favorable for drug delivery [16]. Nanotechnology-based new drug delivery systems can offer significant advantages over the traditional delivery mechanisms in terms of high stability, high carrier capacity, and feasibility of incorporation of both hydrophilic and hydrophobic substances [5-17]. The use of an ideal drug delivery system is decided primarily based on the biophysical and biochemical properties of the targeted drugs being selected for the use in pharmaceutical formulations or biomedical applications [18]. The conventional drug delivery system possesses some issues including limited bioaccessibility and less diffusion capacity into the outer membrane which can be overcome by using an ideal nano-drug delivery system [19]. Ceftizoxime is a third-generation cephalosporin that is highly effective against both Gram-negative and Gram-positive bacteria [20]. It directly acts on the bacterial cell wall and weakens the cell wall formation process by hindering the peptidoglycan formation [21]. The therapeutic levels of ceftizoxime in body tissues produce many adverse effects on the body such as vestibular, renal, and auditory toxicity. Sometimes, it also causes hypersensitivity reactions due to a high dose of the drug [22]. The therapeutic efficacy of ceftizoxime can be increased by developing nanoparticle-based drug delivery systems with minimum side effects [23]. This may be achieved using fabricating drug-polymer conjugate (a natural anionic polymer that binds with cationic moiety) [24]. A convenient and fast solvent displacement method was used for the synthesis of monodispersed drug-loaded polymeric nanoparticles $[25,26]$. In this research work, we prepared ceftizoxime-loaded pectin nanocarriers $(\mathrm{CPN})$ using solvent displacement method and investigated various properties. This allows to obtain promising results to be used in medical application in order to control better the drug delivery.

\section{Materials and Methods}

\subsection{Chemicals and Strains}

Ceftizoxime, pectin, and nutrient agar were bought from HIMEDIA laboratories (P) (Ltd., Maharashtra, India). Calcium chloride $\left(\mathrm{CaCl}_{2}\right)$ pellets and polyvinyl alcohol were procured from S.D. Fine Chemical Ltd., di-Octyl sodium sulfosuccinate (DOSS) and mannitol were acquired from Central Drug House (P) Ltd., New Delhi, India; dichloromethane (DCM) was procured from SRL Ltd.

The microorganisms (Bacillus cereus, Bacillus polymyxa, Enterobacter aerogenes, and Pseudomonas aeruginosa) used for the assay of antibacterial activity of polymeric nanoparticles are enumerated in the lab. All four strains used as a reference, acquired from the National Collection of Dairy Cultures (NCDC), NDRI, Karnal, India. To enhance the growth of a microorganism, nutrient broth (medium) was used. For the media sterilization, the pressure chamber (autoclave) was used for $20 \mathrm{~min}$ at $121^{\circ} \mathrm{C}$. $2 \%$ agar was added whenever a solid medium was required.

\subsection{Nanoformulation Synthesis}

$150 \mathrm{mg}$ of ceftizoxime was mixed in $10 \mathrm{~mL}$ of $0.55 \%$ pectin solution. Di-octyl sodium sulfosuccinate (DOSS) solution was prepared by dissolving $5.50 \mathrm{~g}$ of DOSS in $100 \mathrm{~mL}$ of di-chloro methane (DCM). Add dropwise $30 \mathrm{~mL}$ solution of DOSS in the prepared solution under constant stirring for $10 \mathrm{~min}$. $150 \mathrm{~mL}$ of $3 \%$ polyvinyl alcohol (PVA) was added and allowed for $10 \mathrm{~min}$ sonication. Then, the $\mathrm{CaCl}_{2}$ solution (20 g in $100 \mathrm{~mL}$ of DW) was dropwise, added in the solution under constant stirring for $12 \mathrm{~h}$. After that, the solution was centrifuged at 12,000 rpm for $20 \mathrm{~min}$. The filtrate was used to make pellets and dry in an electric oven at $60{ }^{\circ} \mathrm{C}$ for three hours. Figure 1 displayed the schematic diagram for ceftizoxime-loaded pectin nanocarriers. 


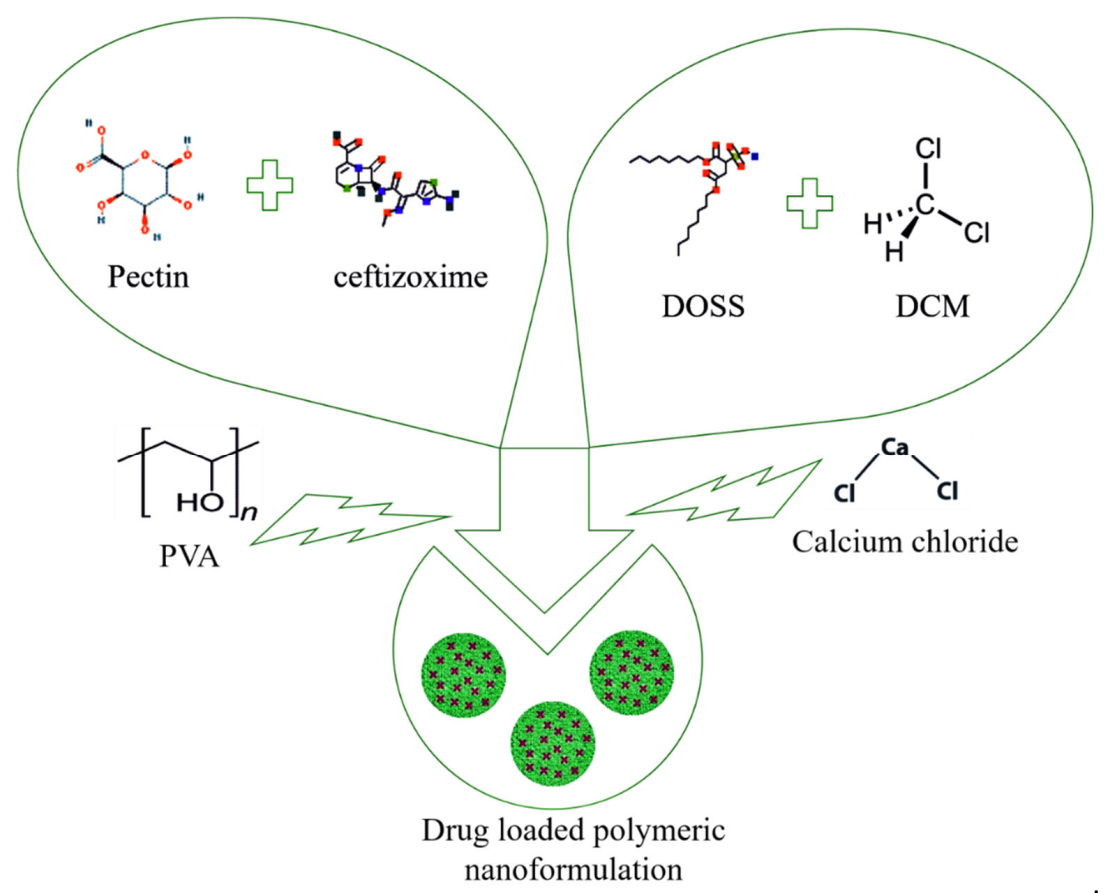

Figure 1. Schematic diagram of nanoformulation fabrication.

\subsection{Optimization of Nanoformulation}

Pectin and di-octyl sodium sulfosuccinate were used as variables and their response was studied with Design-Expert v10. The response surface methodology (RSM) was performed for the given experiment. The concentrations of pectin and di-octyl sodium sulfosuccinate were considered as independent variables. The effects of these two variables were studied for particle size (nm) and the efficiency of encapsulation (\%). These two factors were counted with 9 optimized runs as shown in Table 1. The designed experiment used runs to study the consequences of preparation variables on the particle size (that was taken as $\mathrm{Y}_{1}$ ) and \% efficiency of encapsulation (that was made as $\mathrm{Y}_{2}$ ). The polynomial models included quadratic terms generated for the size of the particle and the ability of encapsulation. The 3D surface graphs were plotted using Design-Expert software.

Table 1. Different experimental runs for optimization.

\begin{tabular}{ccccc}
\hline Sr. No. & $\begin{array}{c}\text { Pectin } \\
(\mathbf{g})\left(\mathbf{X}_{\mathbf{1}}\right)\end{array}$ & $\begin{array}{c}\text { Di-Octyl Sodium } \\
\text { Sulfosuccinate }(\mathbf{g})\left(\mathbf{X}_{\mathbf{2}}\right)\end{array}$ & $\begin{array}{c}\text { Particle Size }(\mathbf{n m}) \\
\left(\mathbf{Y}_{\mathbf{1}}\right)\end{array}$ & $\begin{array}{c}\text { Encapsulation } \\
\text { Efficiency } \mathbf{( \% )}\left(\mathbf{Y}_{\mathbf{2}}\right)\end{array}$ \\
\hline 1 & 0.55 & 1.00 & 207.6 & 67.7 \\
2 & 0.55 & 5.50 & 174.5 & 69.44 \\
3 & 0.55 & 10.00 & 169.2 & 62.63 \\
4 & 0.10 & 1.00 & 152.8 & 63.02 \\
5 & 1.00 & 5.50 & 181.7 & 69.03 \\
6 & 1.00 & 10.00 & 143.5 & 65.3 \\
7 & 0.10 & 10.00 & 189.6 & 57.7 \\
8 & 1.00 & 1.00 & 285.4 & 66.91 \\
9 & 0.10 & 5.50 & 146.3 & 62.44 \\
\hline
\end{tabular}

\subsection{Characterization}

FTIR analysis was used for the confirmation of different functional groups present in the sample. The spectrum of nanoformulation was recorded using the frequency between $600-4000 \mathrm{~cm}^{-1}$ (Perkin Elmer Frontier FTIR, Boston, MA 02118, USA) with the combination of potassium bromide $(\mathrm{KBr})$ pellets [27]. The size of particles and polydispersity index (PDI) of CPN were determined using particle size analyzer (Malvern Instrument, Enigma Business Park, Malvern WR14 1XZ, UK). 
The working principle of the system is based on quasi-elastic light scattering. Transmission electron microscopy (Hitachi H 7500, Chiyoda-ku, Tokyo, Japan) provides information onthe morphology of the sample exhibited by the generated good quality of 2D black and white images. UV-vis spectrophotometer (Shimadzu UV-2450, Milton Keynes, UK) was used to analyze the encapsulation efficiency of nanoformulation. Experiments were performed in triplicate and repeated three times with similar results.

\subsection{Drug Loading and Efficiency of Encapsulation}

The prepared nanoparticulate suspension was centrifuged at 10,000 rpm at $-4{ }^{\circ} \mathrm{C}(4 \mathrm{~K}-15$, Sigma, cooling centrifuge, Osterode, Germany). The obtained supernatant was analyzed by a UV-visible spectrophotometer that revealed absorbance at $298 \mathrm{~nm}$ for the unentrapped drug. Encapsulation efficiency (EE) was calculated by subtracting the amount of unentrapped drug in the supernatant from the total amount of the added drug. The amount of drug encapsulated in $0.1 \mathrm{~g}$ of nanoparticles is known as the loading of the drug. The standard curve equation was used for the determination of the encapsulation efficiency and loading of the drug [28].

$$
\text { Encapsulation efficiency }=\frac{\text { Total Drug }- \text { Unentrapped Drug }}{\text { Total Drug }} \times 100
$$

\subsection{In Vitro Drug Release}

Pure drug and loaded drug nanoparticles were assessed through the dialysis technique [29]. Hot water was taken and dialysis bags were placed in that for $5 \mathrm{~min}$ before use. The bags were further used by rinsing the water. For calculation of dissolution efficacy, $30 \mathrm{mg} C P N$ and $10 \mathrm{mg}$ of ceftizoxime were placed in the dialysis membrane. The dialysis bags were immersed in a PBS solution and allowed for $24 \mathrm{~h}$ stirring. From the saturated solution, $4 \mathrm{~mL}$ of the sample were taken out every hour and the absorbance of the sample was observed using UV-vis spectrophotometry (at $298 \mathrm{~nm}$ ).

\subsection{Standard Calibration Curve}

A reliable, simple, and reproducible method was used for the estimation of drug content in an unknown sample by comparing the unknown to a set of standard samples of known concentration. To determine the concentration of ceftizoxime in the aqueous solution, concentrations of the drug against absorbance $\left(\lambda_{\max } 298 \mathrm{~nm}\right.$ ) were plotted to obtain a calibration curve. The method follows the Beer-Lambert law and measures the concentration of drugs between 1.25 to $20 \mu \mathrm{g} / \mathrm{mL}$ in distilled water. The achieved data of concentration and absorbance were linearly reverting; graph and line equations were calculated. The linearly reverted standard curve of ceftizoxime was plotted in Figure 2. The estimation procedure was found to be reasonably reproducible and fairly sensitive for the concentration range of $1.25-20 \mu \mathrm{g} / \mathrm{mL}$. The related coefficient value in the standard graph was nearly 0.998 . It shows that the drug obeys the Beer-Lambert law in the concentration between 1.25 to $20 \mu \mathrm{g} / \mathrm{mL}$. The method is convenient, inexpensive, reproducible, and sensitive [30]. The experiment was repeated 3 times and the values are given in Table 2.

Table 2. Concentration vs. absorbance of ceftizoxime.

\begin{tabular}{cccc}
\hline S. No. & Concentration $(\mu \mathrm{g} / \mathrm{mL})$ & Absorbance & Standard Deviation (SD) \\
\hline 1. & 1.25 & 0.09 & \pm 0.002 \\
\hline 2. & 2.5 & 0.22 & \pm 0.035 \\
\hline 3. & 5 & 0.48 & \pm 0.09 \\
\hline 4. & 10 & 0.95 & \pm 0.14 \\
\hline 5. & 20 & 1.79 & \pm 0.33 \\
\hline
\end{tabular}




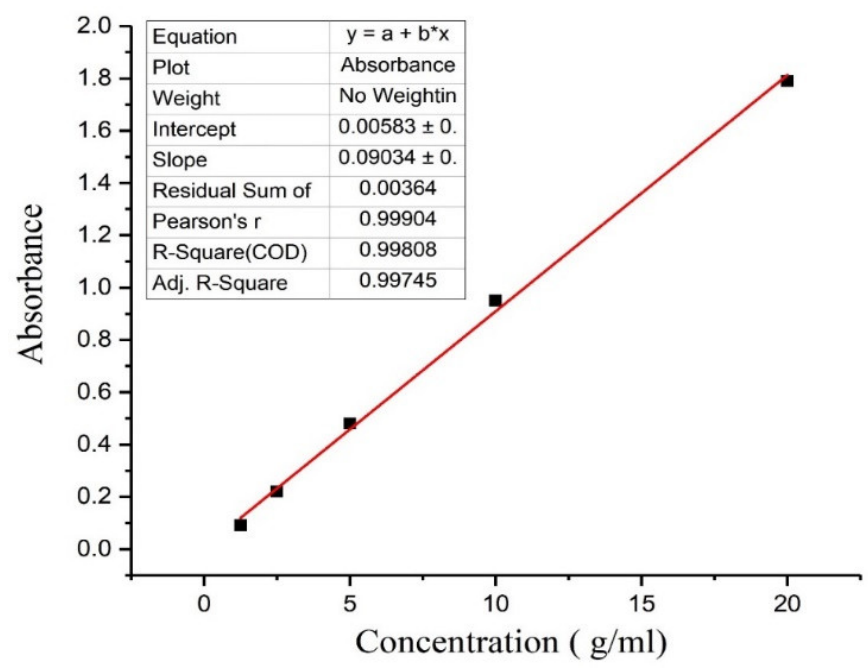

Figure 2. Standard curve of ceftizoxime.

\subsection{Optimization of Nanoformulation}

As shown in Table 1, nine experimental runs were carried out for the optimization of the study. The designed experiment runs according to a standard protocol to find the changes in particle size $\left(\mathrm{Y}_{1}\right)$ and \% encapsulation efficiency $\left(\mathrm{Y}_{2}\right)$. The polynomial models included quadratic equations generated for the size of particle and efficiency of encapsulation. These two factors were evaluated, each at three levels, and 9 experimental runs were carried out.

\subsection{Cytotoxicity Study}

In vitro cytotoxicity of the prepared nanoformulation was evaluated through the MTT assay [31,32]. A mouse fibroblast cell line (L929, ATCC) was used to ensure the biocompatibility of CPN by MTT (3-[4, 5-dimethylthiazole-2-yl]-2, 5 diphenyltetrazolium bromide) assay [33-35]. Briefly, cells were seeded at a density of $5 \times 10^{3}$ cells/well in 96-well plates and cultured for $24 \mathrm{~h}$ in the incubator at $37^{\circ} \mathrm{C}$. The $5 \mu \mathrm{g} / \mathrm{mL}$ concentration of nanoformulation (CPN), ceftizoxime, and pectin were evaluated in comparison to control. Fibroblast cells were treated with $2 \mu \mathrm{g} / \mathrm{mL}$ concentration of aqueous formulation. The culture medium was replaced after $24 \mathrm{~h}$ with fresh media, and incubate for $1 \mathrm{~h}$. After incubation for $1 \mathrm{~h}$, the medium was discarded, the cells were washed twice with phosphate-buffered saline (PBS), and $50 \mathrm{~mL}$ of $5 \mathrm{mg} / \mathrm{mL}$ MTT solution in PBS were added to each well. The content of all wells was detached, and $150 \mu \mathrm{L}$ of DMSO and $25 \mu \mathrm{L}$ of Sorensen's glycine buffer were added to each well to dissolve the substrate for $10 \mathrm{~min}$. The absorptions were measured in triplicate at $570 \mathrm{~nm}$ using a microplate reader. Results were recorded as percentage absorbance relative to untreated control cells. The cytotoxicity assay results were calculated using Equation (2) [36].

$$
\% \text { Cell Viability }=\frac{\text { the absorbance of well containing sample }}{\text { absorbance for untreated control cells }} \times 100
$$

\subsection{Antibacterial Activity}

Antibacterial activity of CPN was evaluated against various bacterial strain viz., Bacillus cereus, Bacillus polymyxa, Enterobacter aerogenes, and Pseudomonas aeruginosa. For the antimicrobial study, the agar well diffusion method was used [37]. These bacteria were grown in lysogeny broth (LB) for $24 \mathrm{~h}$, and $100 \mu \mathrm{L}$ of the LB culture was used to spread over nutrient agar. This procedure uses paper disks (about $6 \mathrm{~mm}$ in diameter) impregnated with $20 \mu \mathrm{g}$ ceftizoxime to test the susceptibility of microorganisms to ceftizoxime. The wells were filled with $50 \mu \mathrm{L}$ suspension of CPN, paper disks (RD), pectin, and distilled water (DW), and incubated at $37^{\circ} \mathrm{C}$ for $24 \mathrm{~h}$ and measured the zone of inhibition using a transparent ruler. The three replicates were used to evaluate the true error in the measured 
responses. These cultures were procured from the National Collection of Dairy Cultures (NCDC), NDRI, Karnal, Haryana, India. The cultures were maintained on nutrient agar for further use as per the condition is given in the MTCC protocol (Table 3).

Table 3. Bacterial strains.

\begin{tabular}{cccc}
\hline Sr. No. & Name of Bacteria & Gram Staining Results & Accession Numbers \\
\hline 1. & Bacillus cereus & Gram positive & NCDC240 \\
2. & Bacillus polymyxa & Gram-positive & NCDC 068 \\
3. & Enterobacter aerogenes & Gram-negative & NCDC 106 \\
4. & Pseudomonas aeruginosa & Gram-negative & NCDC 105 \\
\hline
\end{tabular}

\section{Results and Discussion}

\subsection{Physiochemical Analysis}

FTIR spectrums of pectin, ceftizoxime, and CPN were displayed in Figures 3 and 4 . The spectra of pectin and ceftizoxime revealed the peaks at $3200-3000 \mathrm{~cm}^{-1}$ that confirmed the presence of an $\mathrm{OH}$ group. The chemical groups, along with the respective frequencies, are explained in Table 4. $\mathrm{CPN}$ revealed changes in phases that were recorded as the drug was entrapped in the pectin matrix.
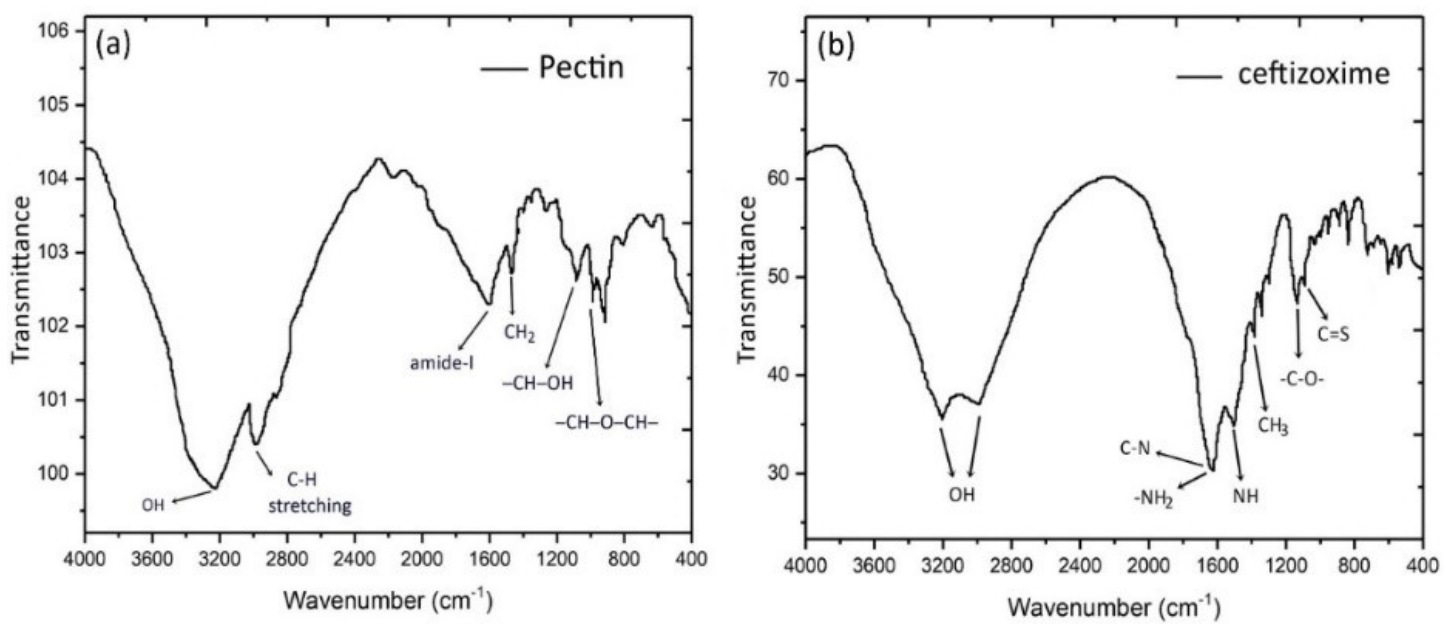

Figure 3. FTIR spectra of pectin (a) and ceftizoxime (b).

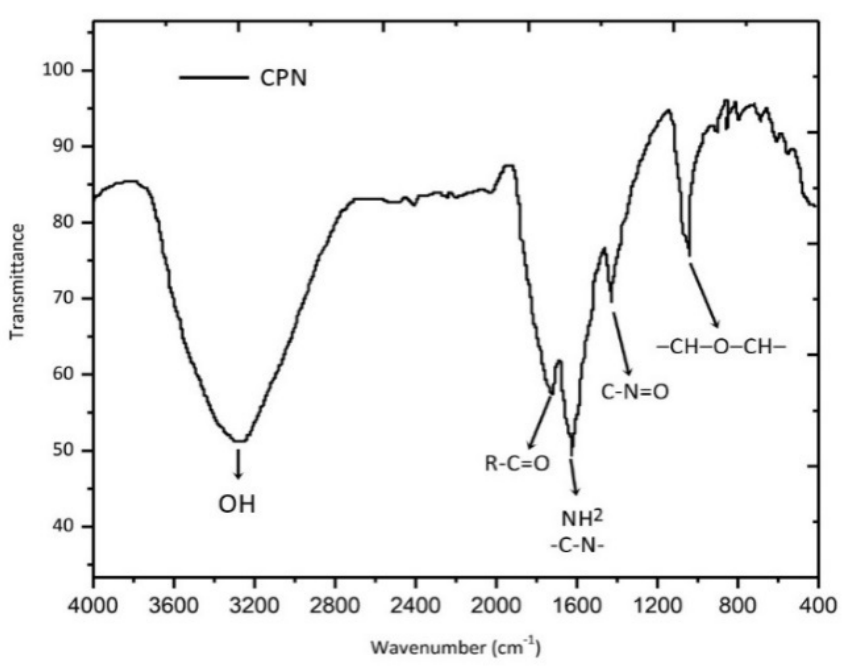

Figure 4. FTIR spectra of CPN. 
Table 4. FTIR spectra of pectin, ceftizoxime, and CPN [38-40].

\begin{tabular}{cc}
\hline Wavenumbers $\left.\mathbf{( c m}^{-\mathbf{1}}\right)$ & Functional Groups \\
\hline $3300-3000$ & $\mathrm{OH}$ \\
2952 & $\mathrm{C}-\mathrm{H}$ \\
1715 & $\mathrm{R}-\mathrm{C}-\mathrm{O}$ \\
1610 & $\mathrm{NH}_{2}, \mathrm{CH}$ stretching \\
1598 & amide-I \\
1490 & $\mathrm{NH}$ stretching \\
1470 & $-\mathrm{CH}_{2}$ scissoring \\
1420 & $\mathrm{C}-\mathrm{N}=\mathrm{O}$ \\
1390 & $\mathrm{CH}$ \\
1180 & $-\mathrm{C}-\mathrm{O}-$ \\
1098 & $\mathrm{C}=\mathrm{S}$ \\
1080 & $-\mathrm{CH}-\mathrm{OH}$ bending vibration \\
1017 & $-\mathrm{CH}-\mathrm{O}-\mathrm{CH}-$ \\
\hline
\end{tabular}

The sample of CPN was lyophilized and dispersed in the double-distilled water with the help of the sonicator. The particle size determined by dynamic light scattering is as shown in Figure 5 and the average size of nanoparticles was found to be $99.5 \pm 3.7 \mathrm{~nm}$. The particle size analysis experiments were performed in triplicate.

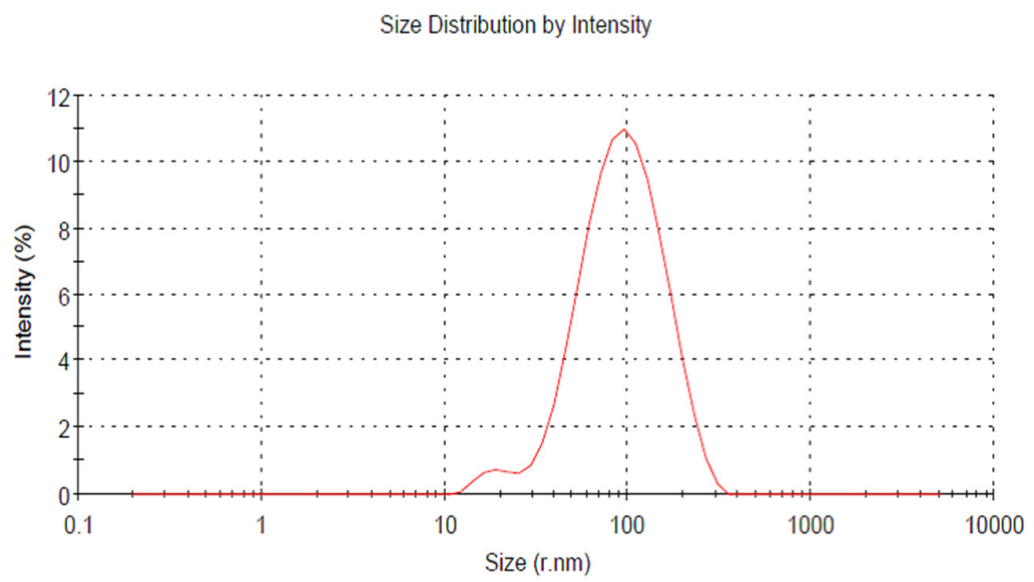

Figure 5. Particle size analysis of CPN (Ceftizoximeloade pectin nanocarriers).

\subsection{Morphological Analysis}

TEM images of polymeric nanoparticles were taken from the Hitachi H 7500, Chiyoda-ku, Tokyo, TEM system. Micrographs of TEM show the shape of CPN (Figure 6A,B), which is almost round in shape and nano in size. The results of TEM shows the size of the particle that is ranging from $70 \mathrm{~nm}$ to $100 \mathrm{~nm}$. Figure 7 revealed the particle size distribution histogram and standard deviation graph. The histogram is a bar graph wherein the $x$-axis represents the CPN particle size and the $y$-axis represents the count.

\subsection{Optimization of Nanoformulation}

Table 1 revealed variables for initial experiments and speculative outcomes concerning the calculated variables on drug encapsulation efficiency and mean particle size. A mathematical relationship between factors and also parameters was shown by 3D surface graphs plots using Design-Expert software, as shown in Figure 8. The size of particles reduced when the concentration of the surfactant was boosted. All the PDI values for the 9 batches are within the acceptable limit. The encapsulation efficiency increased with increasing pectin concentrations and at higher values of di-octyl sodium sulfosuccinate. This is probably due to the formation of more nanoparticles by 
increasing the concentration of the surfactant. This also could be a result of the surfactant-induced reaction and interfacial tension between the two phases used. The positive effect on $\%$ EE may probably have occurred as a result of the ability of pectin to encapsulate large amounts of ceftizoxime due to an increase in the mass of pectin. Supplementary arithmetical considerations for all factors were scrutinized through the ANOVA test as depicted in Table 5. The results of the response surface methodology, best-fitted polynomial models, and ANOVA results are provided below:

$$
\begin{aligned}
& \text { P. S. }=+161.78-8.43 \times A-2.68 \times B+3.97 \times A B-38.47 \times A^{2}-7.02 \times B^{2} \\
& \text { E. E. }=+68.65+3.01 \times A-2.00 \times B+0.93 \times A B-2.52 \times A^{2}-3.09 \times B^{2}
\end{aligned}
$$
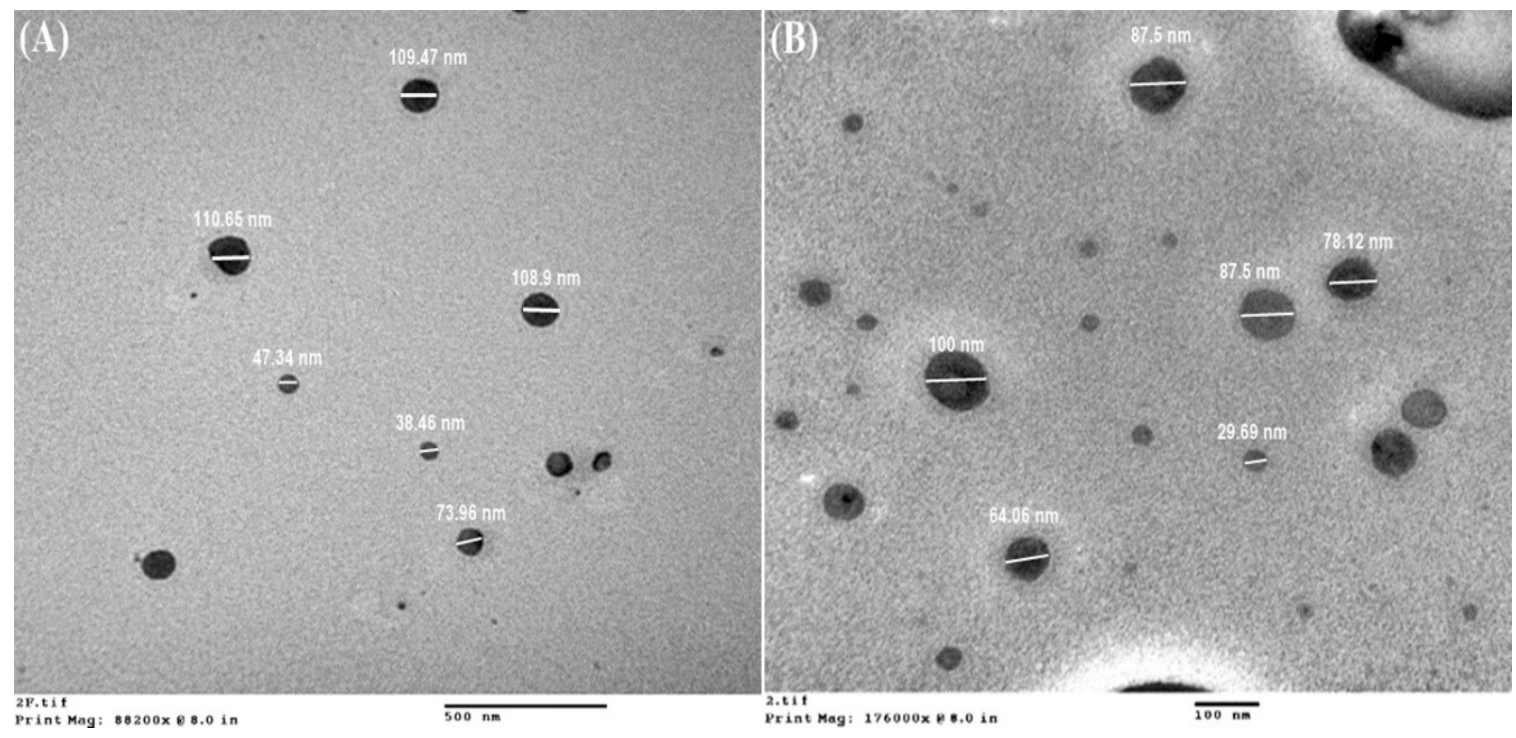

Figure 6. TEM images of CPN, subfigure (A) represents particles size at $500 \mathrm{~nm}$ scale and subfigure (B) represents particles size at $100 \mathrm{~nm}$ scale.
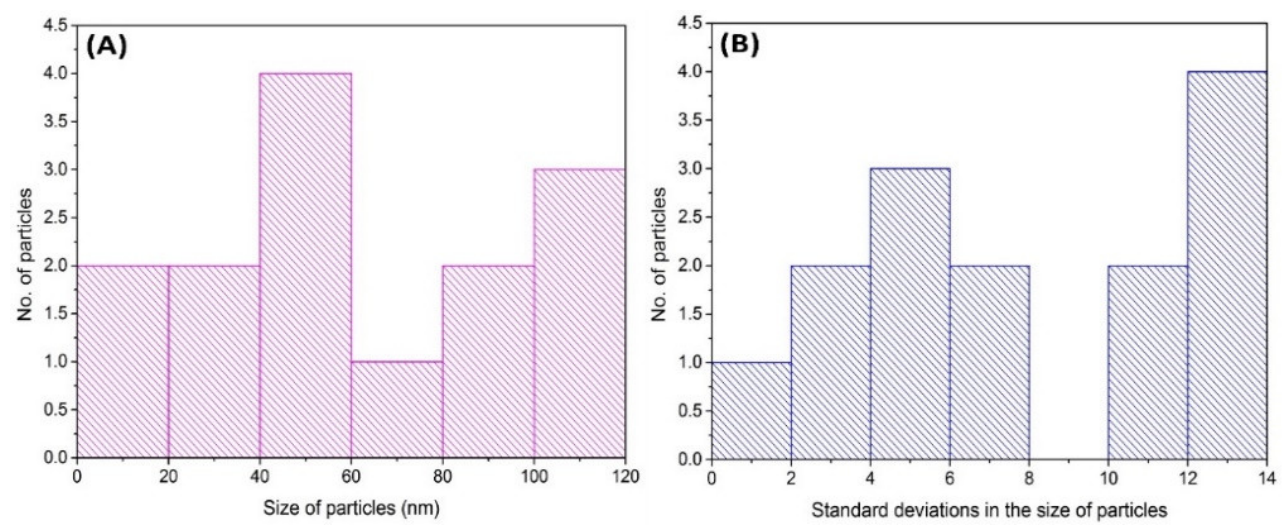

Figure 7. Particle size distribution histogram (A) and standard deviation (B) graph.

Table 5. Arithmetical consideration for optimization.

\begin{tabular}{ccccccccccc}
\hline & \multicolumn{1}{c}{ Model } & \multicolumn{3}{c}{ Lack of Fit } \\
\hline $\begin{array}{c}\text { Response } \\
\text { Factor }\end{array}$ & $\begin{array}{c}\text { Prob. } \\
\boldsymbol{>} \boldsymbol{F}\end{array}$ & $\boldsymbol{R}^{\mathbf{2}}$ & $\begin{array}{c}\boldsymbol{F} \\
\text { Value }\end{array}$ & $\begin{array}{c}\text { Pred. } \\
\boldsymbol{R}^{\mathbf{2}}\end{array}$ & $\begin{array}{c}\text { Adeq. } \\
\text { Prec. }\end{array}$ & $\mathbf{C . V}$. & $\begin{array}{c}\text { Adjust. } \\
\boldsymbol{R}^{\mathbf{2}}\end{array}$ & $\begin{array}{c}\text { Std. } \\
\text { Dev. }\end{array}$ & $\begin{array}{c}\text { Prob. } \\
\boldsymbol{>} \boldsymbol{F}\end{array}$ & $\begin{array}{c}\boldsymbol{F} \\
\text { Value }\end{array}$ \\
\hline $\mathrm{Y}_{1}$ & 0.0045 & 0.9878 & 48.41 & 0.8817 & 21.322 & 4.30 & 0.9674 & 7.88 & 0.527 & 9.17 \\
$\mathrm{Y}_{2}$ & 0.0029 & 0.9909 & 65.06 & 0.9266 & 23.517 & 0.96 & 0.9756 & 0.63 & 0.0180 & 20.30 \\
\hline
\end{tabular}


(A)

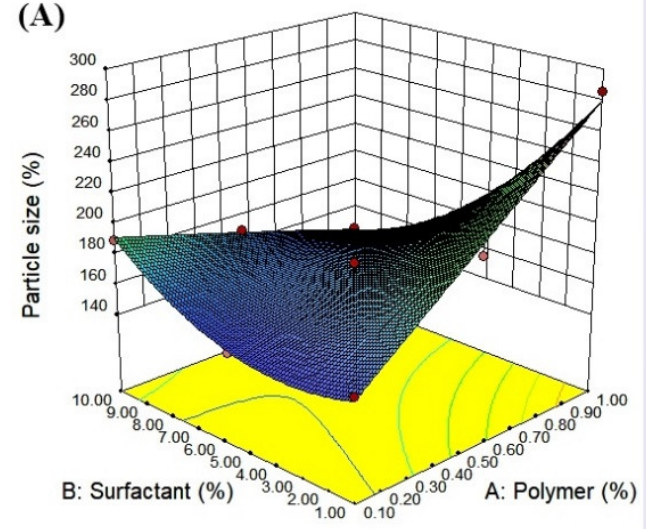

(B)

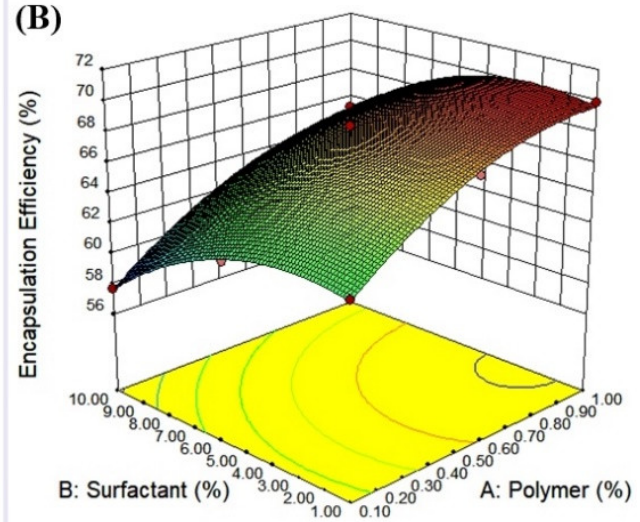

Figure 8. (A) Response surface graph showing the effects of pectin and di-octyl sodium sulfosuccinate (DOSS) concentration on the particle size and (B) the effectiveness of drug encapsulation in nanoparticles.

The fitting outcomes showed that the optimized nanoparticles with high entrapment efficiency $(69.44 \%)$ and lesser particle size $(174.5 \mathrm{~nm})$ were obtained with $1 \%$ pectin and $10 \%$ di-octyl sodium sulfosuccinate concentrations.

\subsection{Drug Loading and Encapsulation Efficiency}

The amount of drug loading in the pectin nanoparticles was determined by an ultraviolet-visible spectrophotometer. The unbounded drug was present in the supernatant, collected through centrifugation, and measured at $298 \mathrm{~nm}$. The efficiency of encapsulation and loading of the drug was determined by the standard curve equation:

$$
\mathrm{y}=11.04 \mathrm{x}-0.049
$$

The peak of the supernatant of an optimized batch of CPN is shown in Figure 9. The total weight of nanoparticles was $3.69 \mathrm{gm}$, and the total amount of drug encapsulated was $97.06 \mathrm{mg}$. Drug loading was found to be $21 \%$ and encapsulation efficiency was counted as $69.4 \%$.

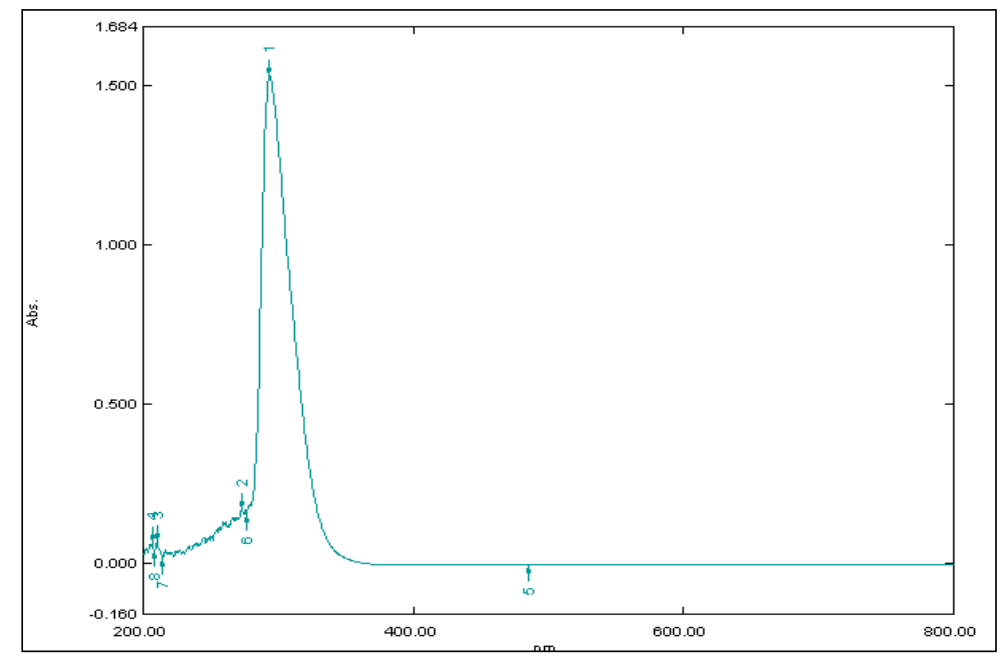

Figure 9. The UV-visible spectrum of $\mathrm{CPN}$.

\subsection{In Vitro Drug Release}

The drug release profile of the pure drug and the nanoparticulate system is provided in Table 4. Ceftizoxime escaped rapidly from the dialysis bag and showed the burst release from 
the nanoformulation that indicated the release of $9.71 \%$ after $24 \mathrm{~h}$. The presence or entrapment of drug on the core of the polymer matrix makes formulation slow and release sustained. The comparative analysis of the drug release profile of ceftizoxime and CPN (Figure 10) indicated that the effect of ceftizoxime encapsulation in pectin provided a sustained release.

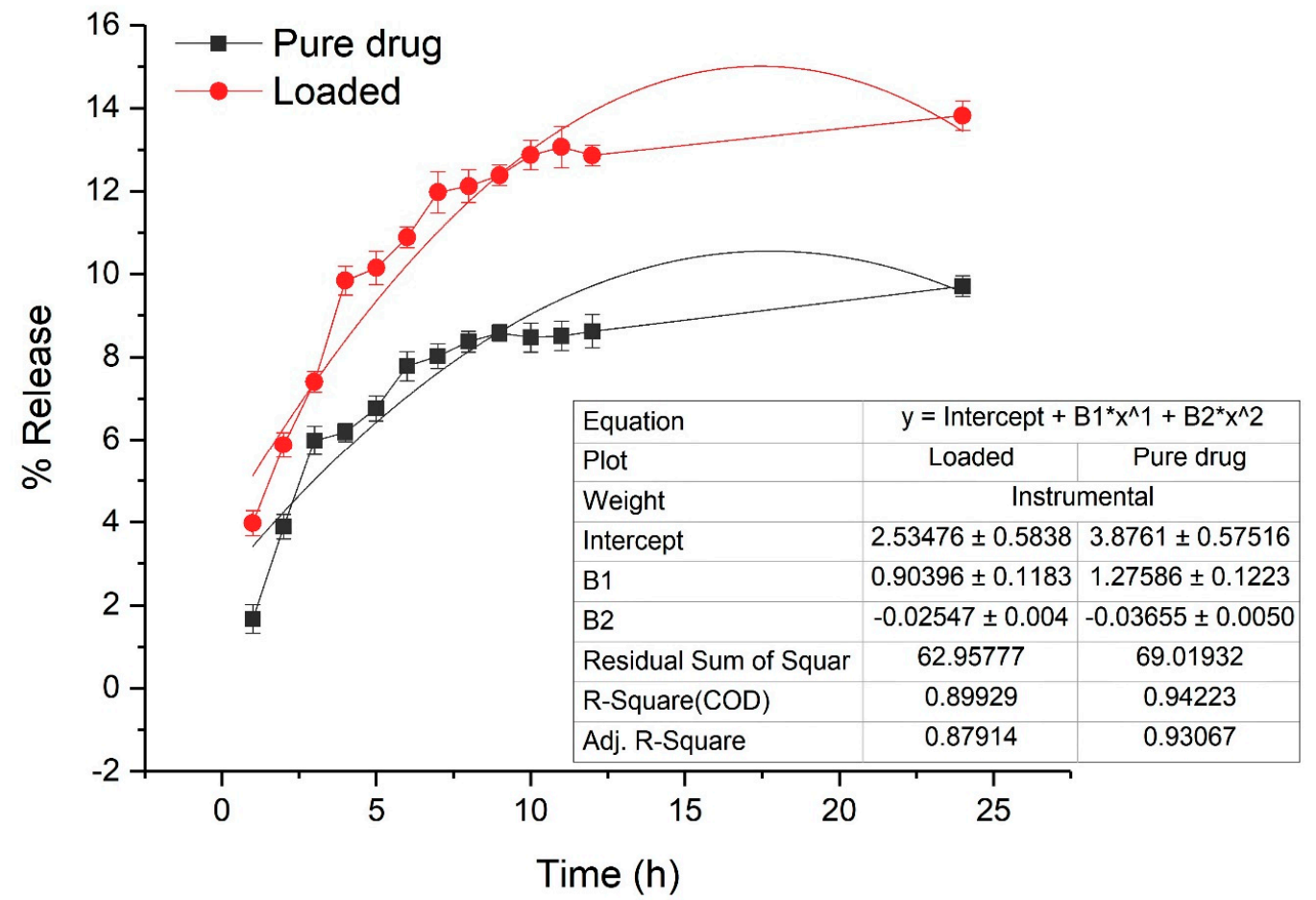

Figure 10. In vitro drug releases at different time intervals.

\subsection{In Vitro Cytotoxicity}

The percentage viability of fibroblast cells incubated with nanoformulation (CPN) is shown in Figure 11. The CPN did not persuade any significant cytotoxic effect, even at the higher concentrations. As the concentration of CPN increases, the percentage of cell viability also decreased. For the comparative analysis, cytotoxicity of pectin (without drug) was also assessed against fibroblast cells using the MTT assay. Overall, both pectin and ceftizoxime-loaded pectin nanocarriers did not show significant toxicity against fibroblast cells.

\subsection{Antibacterial Activity}

The antibacterial activity of CPN and the reference drug (RD), ceftizoxime, against Bacillus cereus, Bacillus polymyxa, Enterobacter aerogenes, and Pseudomonas aeruginosa, are shown in Figure 12. The comparative zones of inhibition (ZoI) were analyzed, and the results are described in Table 6. CPN showed better antibacterial activity in comparison to the reference drug ceftizoxime and pectin. The highest activity was observed against Enterobacter aerogenes, as evident by the formation of an inhibition zone of $28 \mathrm{~mm}$. The antibacterial analysis was performed in triplicate and then the inhibition zone was calculated.

Table 6. Zone of inhibition (ZoI) for RD vs. CPN with standard deviation.

\begin{tabular}{ccc}
\hline Bacterial Strain & CPN & RD \\
\hline Bacillus cereus & $16 \pm 1.5 \mathrm{~mm}$ & $14 \pm 0.3 \mathrm{~mm}$ \\
Bacillus polymyxa & $18 \pm 1.8 \mathrm{~mm}$ & $10 \pm 0.2 \mathrm{~mm}$ \\
Enterobacter aerogenes & $28 \pm 2.3 \mathrm{~mm}$ & $12 \pm 0.2 \mathrm{~mm}$ \\
Pseudomonas aeruginosa & $22 \pm 1.9 \mathrm{~mm}$ & $12 \pm 0.1 \mathrm{~mm}$ \\
\hline
\end{tabular}




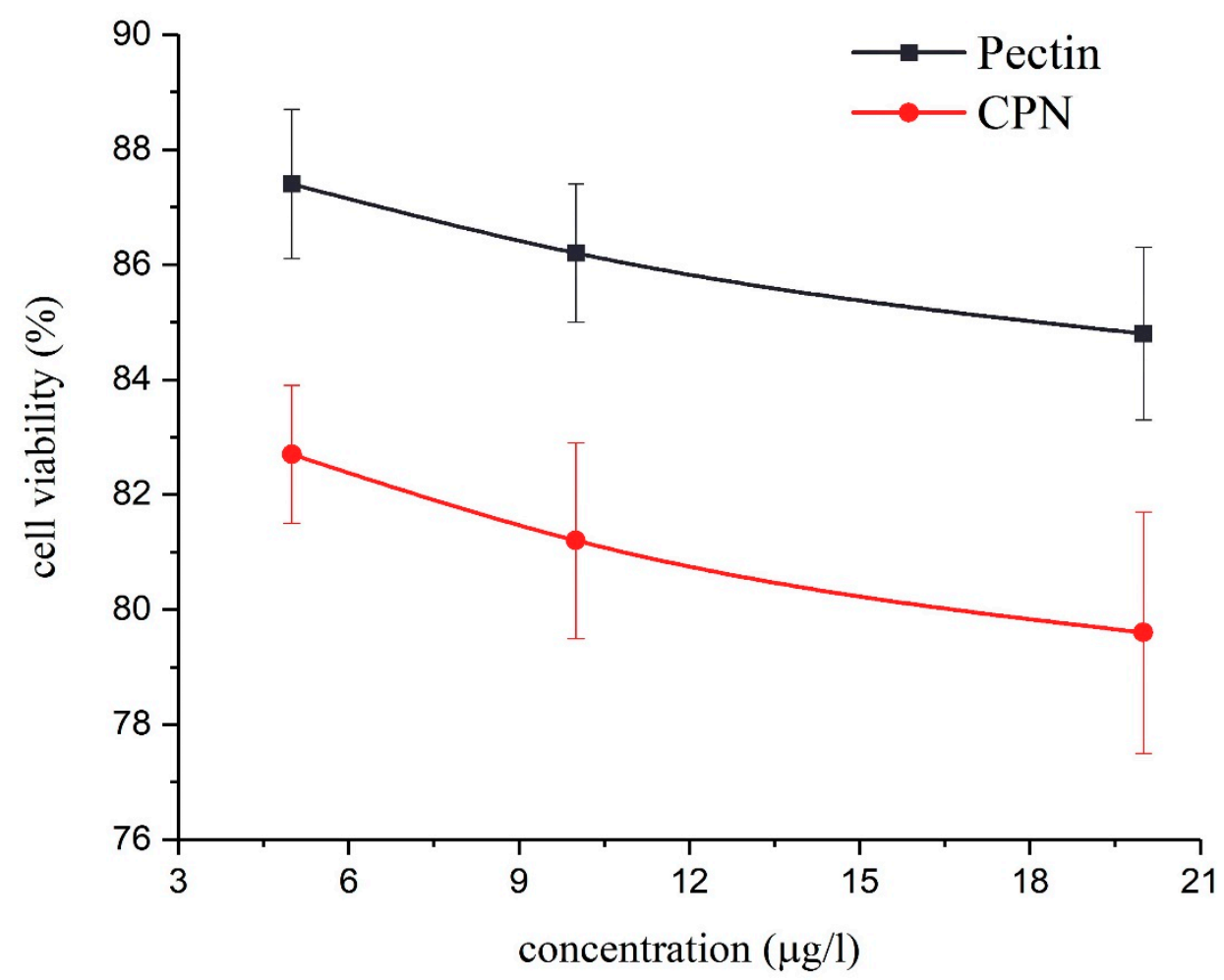

Figure 11. Comparative analysis of the percentage of cell viability against pectin and CPN.
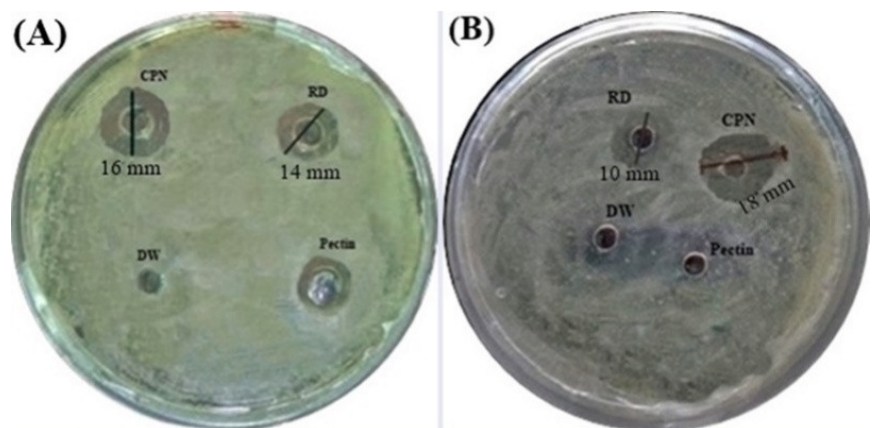

(D)

(C)
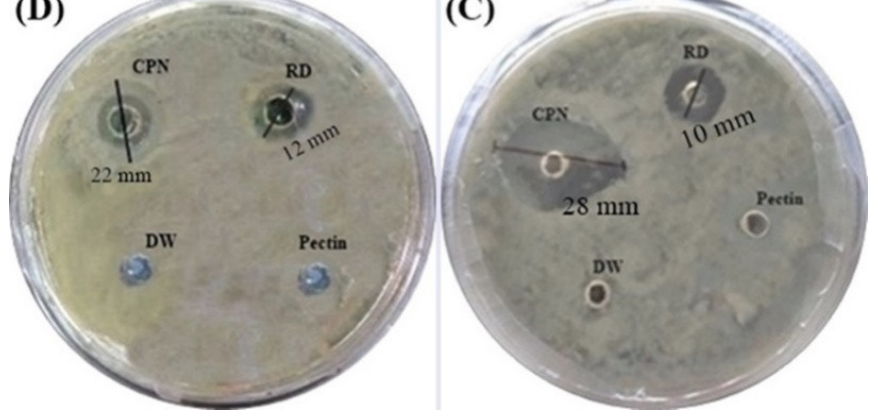

Figure 12. Zone of inhibition of $\mathrm{CPN}$, and RD against Bacillus cereus (A), Bacillus polymyxa (B), Enterobacter aerogenes (C), and Pseudomonas aeruginosa (D).

\section{Conclusions}

In conclusion, ceftizoxime-loaded pectin nanoparticles (CPN) were successfully prepared using the solvent displacement method and were further optimized using a two-level factorial design. TEM analysis revealed 70-100 nm-sized round-shaped nanoparticles, whereas the presence of the drug in nanoparticles was confirmed with the aid of FTIR spectra. The drug loading in the pectin 
nanoparticles was found to be $21 \%$ and encapsulation efficiency was calculated as $69.4 \%$. Antibacterial activity of ceftizoxime-loaded pectin nanoparticles showed a better zone of inhibition than the reference drug (ceftizoxime) because of the higher efficacy of the drug for a long time. CPN did not show any significant toxicity against fibroblast cell lines. In this way, ceftizoxime-loaded pectin nanocarriers can be used for their application in controlled drug delivery. However, further suitable animal model (in vivo) studies are still required to validate the results of in vitro evaluation and the use of CPNs for drug delivery applications.

Author Contributions: P.K.: conceptualization, methodology, investigation, writing-original draft; V.K.: validation, formal analysis, visualization, software; R.K.: resources, writing-review and editing, supervision, data curation; C.I.P.: writing-review and editing. All authors have read and agreed to the published version of the manuscript.

Funding: This research received no external funding.

Conflicts of Interest: The authors declare no conflict of interest.

\section{References}

1. Homayun, B.; Lin, X.; Choi, H.J. Challenges and recent progress in oral drug delivery systems for biopharmaceuticals. Pharmaceutics 2019, 11, 129. [CrossRef] [PubMed]

2. Matsui, H.; Shimokawa, O.; Kaneko, T.; Nagano, Y.; Rai, K.; Hyodo, I. The pathophysiology of non-steroidal anti-inflammatory drug (NSAID)-induced mucosal injuries in stomach and small intestine. J. Clin. Biochem. Nutr. 2011, 48, 107-111. [CrossRef]

3. Wen, H.; Jung, H.; Li, X. Drug Delivery Approaches in Addressing Clinical Pharmacology-Related Issues: Opportunities and Challenges. AAPS J. 2015, 17, 1327-1340. [CrossRef] [PubMed]

4. Park, K. Drug Delivery Research: The Invention Cycle. Mol. Pharm. 2016, 13, 2143-2147. [CrossRef] [PubMed]

5. Patra, J.K.; Das, G.; Fraceto, L.F.; Campos, E.V.R.; del Pilar Rodriguez-Torres, M.; Acosta-Torres, L.S.; Diaz-Torres, L.A.; Grillo, R.; Swamy, M.K.; Sharma, S.; et al. Nano based drug delivery systems: Recent developments and future prospects. J. Nanobiotechnol. 2018, 16, 71. [CrossRef] [PubMed]

6. Jain, D.; Raturi, R.; Jain, V.; Bansal, P.; Singh, R. Recent technologies in pulsatile drug delivery systems. Biomatter 2011, 1, 57-65. [CrossRef]

7. Hadizadeh, M.; Toraji, A. Amoxicillin-Loaded Polymeric Nanoparticles of Less than $100 \mathrm{~nm}$ : Design, Preparation and Antimicrobial Activity Against Methicillin-Resistant Staphylococcus aureus. Iran. J. Sci. Technol. Trans. A Sci. 2019, 43, 379-386. [CrossRef]

8. Motiei, M.; Kashanian, S.; Azandaryani, A.H. Effect of Fabrication Parameters on the Physiochemical Properties of Amphiphilic Chitosan Nanoparticles. Iran. J. Sci. Technol. Trans. A Sci. 2018, 42, 1873-1879. [CrossRef]

9. Singh, P.K.; Jairath, G.; Ahlawat, S.S. Nanotechnology: A future tool to improve quality and safety in meat industry. J. Food Sci. Technol. 2016, 53, 1739-1749. [CrossRef]

10. Martău, A.G.; Mihai, M.; Vodnar, C.D. The Use of Chitosan, Alginate, and Pectin in the Biomedical and Food Sector-Biocompatibility, Bioadhesiveness, and Biodegradability. Polymers 2019, 11, 1837. [CrossRef]

11. Minzanova, S.T.; Mironov, V.F.; Arkhipova, D.M.; Khabibullina, A.V.; Mironova, L.G.; Zakirova, Y.M.; Milyukov, V.A. Biological Activity and Pharmacological Application of Pectic Polysaccharides: A Review. Polymers 2018, 10, 1407. [CrossRef] [PubMed]

12. Sriamornsak, P. Application of pectin in oral drug delivery. Expert Opin. Drug Deliv. 2011, 8, 1009-1023. [CrossRef]

13. Srivastava, P.; Malviya, R. Sources of pectin, extraction and its applications in pharmaceutical industry-An overview. Indian J. Nat. Prod. Resour. 2011, 2, 10-18.

14. Thakur, B.R.; Singh, R.K.; Handa, A.K.; Rao, M.A. Chemistry and uses of pectin-A review. Crit. Rev. Food Sci. Nutr. 1997, 37, 47-73. [CrossRef] [PubMed]

15. Lara-Espinoza, C.; Carvajal-Millán, E.; Balandrán-Quintana, R.; López-Franco, Y.; Rascón-Chu, A. Pectin and Pectin-Based Composite Materials: Beyond Food Texture. Molecules 2018, 23, 942. [CrossRef] 
16. Munarin, F.; Tanzi, M.C.; Petrini, P. Advances in biomedical applications of pectin gels. Int. J. Biol. Macromol. 2012, 51, 681-689. [CrossRef]

17. Li, C.; Wang, J.; Wang, Y.; Gao, H.; Wei, G.; Huang, Y.; Yu, H.; Gan, Y.; Wang, Y.; Mei, L.; et al. Recent progress in drug delivery. Acta Pharm. Sin. B 2019, 9, 1145-1162. [CrossRef]

18. Mabrouk, M.; Rajendran, R.; Soliman, E.I.; Ashour, M.M.; Beherei, H.H.; Tohamy, M.K.; Thomas, S.; Kalarikkal, N.; Arthanareeswaran, G.; Das, B.D. Nanoparticle- and Nanoporous-Membrane-Mediated Delivery of Therapeutics. Pharmaceutics 2019, 11, 294. [CrossRef]

19. Canaparo, R.; Foglietta, F.; Giuntini, F.; Della Pepa, C.; Dosio, F.; Serpe, L. Recent Developments in Antibacterial Therapy: Focus on Stimuli-Responsive Drug-Delivery Systems and Therapeutic Nanoparticles. Molecules 2019, 24, 1991. [CrossRef]

20. Flaherty, J.F.; Barriere, S.L. Third-generation cephalosporins: A critical evaluation. Am. J. Hosp. Pharm. 1984, 41, 1652-1663.

21. Liu, Y.; Breukink, E. The Membrane Steps of Bacterial Cell Wall Synthesis as Antibiotic Targets. Antibiotics 2016, 5, 28. [CrossRef] [PubMed]

22. Richards, D.M.; Heel, R.C. Ceftizoxime. Drugs 1985, 29, 281-329. [CrossRef] [PubMed]

23. Singh, R.; Lillard, J.W. Nanoparticle-based targeted drug delivery. Exp. Mol. Pathol. 2009, 86, $215-223$. [CrossRef] [PubMed]

24. Feng, Q.; Tong, R. Anticancer nanoparticulate polymer-drug conjugate. Bioeng. Transl. Med. 2016, 1, $277-296$. [CrossRef] [PubMed]

25. Beck-Broichsitter, M.; Rytting, E.; Lebhardt, T.; Wang, X.; Kissel, T. Preparation of nanoparticles by solvent displacement for drug delivery: A shift in the "ouzo region" upon drug loading. Eur. J. Pharm. Sci. 2010, 41, 244-253. [CrossRef]

26. Parkash, C.; Singh, S.; Datusalia, A.; Deep, A. Development and characterization of nanoparticles of glibenclamide by solvent displacement method. Acta Pol. Pharm. 2010, 67, 283-290.

27. Geetha, N.; Harini, K.; Joseph, M.; Sangeetha, R.; Venkatachalam, P. A Comparison of Microwave Assisted Medicinal Plant Extractions for Detection of Their Phytocompounds Through Qualitative Phytochemical and FTIR Analyses. Iran. J. Sci. Technol. Trans. A Sci. 2019, 43, 397-407. [CrossRef]

28. Sun, S.-B.; Liu, P.; Shao, F.-M.; Miao, Q.-L. Formulation and evaluation of PLGA nanoparticles loaded capecitabine for prostate cancer. Int. J. Clin. Exp. Med. 2015, 8, 19670-19681.

29. Jain, A.K.; Thareja, S. In vitro and in vivo characterization of pharmaceutical nanocarriers used for drug delivery. Artif. Cells, Nanomed. Biotechnol. 2019, 47, 524-539. [CrossRef]

30. Erchiqui, F. Analysis and Evaluation of Power Formulations for Wood and Hardboard Using Radio Frequency and Microwave Energy. Dry. Technol. 2014, 32, 946-959. [CrossRef]

31. Eatemadi, A.; Darabi, M.; Afraidooni, L.; Zarghami, N.; Daraee, H.; Eskandari, L.; Mellatyar, H.; Akbarzadeh, A. Comparison, synthesis and evaluation of anticancer drug-loaded polymeric nanoparticles on breast cancer cell lines. Artif. Cells Nanomed. Biotechnol. 2016, 44, 1008-1017. [CrossRef] [PubMed]

32. Kumar, P.; Saini, M.; Kumar, V.; Dehiya, B.S.; Sindhu, A.; Fouad, H.; Ahmad, N.; Mahmood, A.; Hashem, M. Polyethylene Glycol (PEG) Modified Porous $\mathrm{Ca}_{5}\left(\mathrm{PO}_{4}\right)_{2} \mathrm{SiO}_{4}$ Bioceramics: Structural, Morphologic and Bioactivity Analysis. Coatings 2020, 10, 538. [CrossRef]

33. Kumar, P.; Saini, M.; Dehiya, B.S.; Umar, A.; Sindhu, A.; Mohammed, H.; Al-Hadeethi, Y.; Guo, Z. Fabrication and in-vitro biocompatibility of freeze-dried CTS-nHA and CTS-nBG scaffolds for bone regeneration applications. Int. J. Biol. Macromol. 2020, 149, 1-10. [CrossRef] [PubMed]

34. Kumar, P.; Dehiya, B.S.; Sindhu, A. Synthesis and characterization of nHA-PEG and nBG-PEG scaffolds for hard tissue engineering applications. Ceram. Int. 2019, 45, 8370-8379. [CrossRef]

35. Kumar, P.; Dehiya, B.S.; Sindhu, A. Ibuprofen-Loaded CTS/nHA/nBG Scaffolds for the Applications of Hard Tissue Engineering. Iran. Biomed. J. 2019, 23, 190-199. [CrossRef]

36. Kumar, P.; Kumar, V.; Kumar, R.; Kumar, R.; Pruncu, C.I. Fabrication and characterization of $\mathrm{ZrO}_{2}$ incorporated $\mathrm{SiO}_{2}-\mathrm{CaO}-\mathrm{P}_{2} \mathrm{O}_{5}$ bioactive glass scaffolds. J. Mech. Behav. Biomed. Mater. 2020, 109, 103854. [CrossRef]

37. Balouiri, M.; Sadiki, M.; Ibnsouda, S.K. Methods for in vitro evaluating antimicrobial activity: A review. J. Pharm. Anal. 2016, 6, 71-79. [CrossRef]

38. Mishra, R.; Datt, M.; Pal, K.; Banthia, A. Preparation and characterization of amidated pectin based hydrogels for drug delivery system. J. Mater. Sci. Mater. Med. 2008, 19, 2275-2280. [CrossRef] 
39. Liu, Y.; Sun, Y.; Guanglong, D.; Geng, Q.; Zhu, J.; Guo, M.; Duan, Y.; Wang, B. Synthesis, Characterization, and Application of Microbe-Triggered Controlled-Release Kasugamycin-Pectin Conjugate. J. Agric. Food Chem. 2015, 63, 4263-4268. [CrossRef]

40. Moreno, A.; Salgado, H. Development and Validation of the Quantitative Analysis of Ceftazidime in Powder for Injection by Infrared Spectroscopy\#. Phys. Chem. 2012, 2, 6-11.

(C) 2020 by the authors. Licensee MDPI, Basel, Switzerland. This article is an open access article distributed under the terms and conditions of the Creative Commons Attribution (CC BY) license (http://creativecommons.org/licenses/by/4.0/). 